Edith Cowan University

Research Online

School of Psychology and Social Science Presentations

2012

Social Capital in Metropolitan Playgroups : A Qualitative Analysis of Early Parental Interactions

Hebba Gibson

Edith Cowan University

Follow this and additional works at: https://ro.ecu.edu.au/spsyc_pres

Part of the Psychology Commons

Supervisors: Dr Bronwyn Harman

This Presentation is posted at Research Online.

https://ro.ecu.edu.au/spsyc_pres/11 


\section{Social Capital in Metropolitan Playgroups - A Qualitative Analysis of Early Parental Interactions}

\section{HEBBA GIBSON}

SCHOOL OF PSYCHOLOGY AND SOCIAL SCIENCE

SUPERVISOR: BRONWYN HARMAN 


\section{Introduction}

\section{Background \& Literature Review}

- Parents' ability to rely on their peers to access different types of support is vital to their health and well-being. This ability is said to reflect their levels of Social Capital.

- Playgroups are hubs for fostering Social Capital that benefits parents. Empirical evaluations of Playgroups that examine their effectiveness using measures of Social Capital are extremely scarce.

- The literature also shows that there are inequalities in Social Capital which reflects social, economic and other types of inequalities between individuals and can enforce dominant ideologies. 


\section{This Study}

- This study used social capital theory to investigate how parents form social ties through bonding bridging and linking.

- Different people connect differently to each other, and so this provided a basis for analysis for this study.

- Parents were asked to share their lived experiences during playgroups, their connections with other parents, and their subjective evaluation of how they were supported.

- The nature and type of social ties, were be related back to the levels of Social resources accessed by parents. 


\section{Research Questions}

1. What types of the social interactions occur between new parents in Playgroups and do the qualities of social ties impact on parental access to Social Capital resources?

2. Are there Social Capital inequalities in Playgroups? 


\section{Research Design}

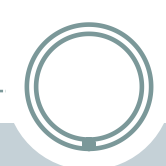

- Research paradigm. A qualitative design using phenomenology was used to understand the lived experience of parents during playgroups, their connections with other parents and their subjective evaluation of how they were supported. Semi-structured in-depth interviews were conducted with fifteen first and second time parents who were recruited via information letters emailed to metropolitan Playgroups

- Participants. Fourteen female and one male research participants were recruited through information letters that were emailed to metropolitan playgroups. Ages ranged from early twenties to mid forties. Parents had up to 2 children each. Participants varied across levels of socio-economics, educational background, culture and marital status. 


\section{Research Design}

- Procedure. Information letters and a consent forms were emailed to Playgroup presidents across a number of playgroups in Perth who distributed them to their members. A meeting was arranged with interested members. In depth voice recorded interviews were conducted using a few guiding questions. Data was transcribed verbatim immediately after each interview.

- Rigour was maintained through : 1 . member checking 2 . reflective note taking 3 . use of direct quotations against each theme 4 . cross-validation by research supervisor.

- Analysis. Thematic data analysis was conducted on the transcripts. Patterns in the data were identified and gave rise to a number of overarching themes. 


\section{Findings and Interpretation}

The three themes emerged from the data

1. 'Getting together' relates to group formation, and parents finding commonalities. There is evidence for homophilous bonding and creating homogeneous groups. Parents felt a strong need to associate with other parents and joining Playgroups fulfilled this need.

2. 'Generating stocks of Social Capital' describes the many benefits accessed by parents as a result of their newly formed relationships. The stronger the ties the more access to Social Capital. Weak ties were related to moderate levels of Social Capital. Some parents 'got ahead' while others 'got by'.

3. 'Missing out'. Relates to parents who had trouble connecting with others or were excluded. Some Playgroup experiences were dysfunctional and negative. These parents 'missed out' on Social Capital opportunities . 


\section{Theme 1. 'Getting Together'}

- Many of the parents interviewed expressed that they had a need to associate with other new parents, rather than seek out support from old friendships.

"Like my other friends don't necessarily want to hear about what my child is doing all the time... whereas the other mums there with kids the same age are more than willing to have those conversation:

- Going through the trial of early parenting became a basis for conversations and emotional support. Their discourse demonstrated an attempt to seek out similarities and overlook differences.

"I think everyone was different we all have different background and personalities, but we were all united in the common need for support"

- Homophilous ties such shared norms \& forming homogenous groups "we are a fairly homogenous group... we are all white Australians, there was one girl who is Malaysian but she went back to work fairly quickly afterwards and sort of just dropped off from the rest of the group, she didn't clique with it but we cliqued quite well" 


\section{Theme 2. Creating Stocks of Social Capital}

\section{Parents "Getting by" -}

The network provided protection against isolation often felt in the early months of having a newborn "I found it very handy, in that I just needed to get out of the house and talk to other women"

Playgroup provided tangible and intangible resources to parents. "sense of community", selling second hand equipment.

Bridging knowledge about developmental norms for their children "just to see that everything is normal basically, if they (children) don't do everything just the same but it's still normal."

Strong support for members going through adversity. "I had a miscarriage a couple of months ago, and they have all been really supportive with that" 


\section{Creating Stocks of Social Capital cont...}

\section{Parents "Getting by"}

Strong bonds between some parents resulted in cliques or dyads. These parents carried out extra-group activities, had more partner involvement and became good friends. These tight-knit groups had more intimacy and trust. They shared special favours and privileges not afforded to other members.

"Some of them go on holidays together.. they are very close friends outside of playgroup.. So they invite each other to parties and all that...they are close friends.. then they are the others I would say" 


\section{Theme 3. Missing Out}

- Isolation and social exclusions- Parents, who expressed uniqueness to their group in some way, challenged the group norms and consequently felt a social distance. This shows there are different types of isolation, as in social and emotional isolation.

- Parents who were shy and less outgoing were often overlooked by the rest of the group.

- Some were singled out unanimously by the group for not conforming.

- Gendering - being a male in female territory was difficult.

- Same-sex-couple mother driven away after challenging norms. 


\section{Missing Out cont.}

Conformity: Dominant members, passive members and group dominance.

- Dominance, racial remarks, judgement and toxicity of Playgroup environment

- 'I supposeyou would have to deal with all those migrants', she said. And there was me (a migrant) and a girl from J apan sitting there"

- 'T guess it's become apparent that although we all had children at the same time, once that necessity to discuss settling and feeding and whatever all the other issues are...there is not a lot that we end up having in common at this age..we were just a group who had their children at the same time." 


\section{Answers To The Research Questions}

1. Social interactions in Playgroups produced different types of connections between parents, ranging from strong cliques to total fragmentation. This in turn impacted on their levels of Social Capital resources.

2. Literature on Social Capital inequality was confirmed. Social Capital was unevenly distributed across Playgroup members through dynamic processes. Forces that create cohesion through strong bonds between individuals, simultaneously produce exclusions of others. Some got by, others got ahead, and a few missed out on social resources. 


\section{Conclusions}

Playgroups are micro-systems that foster Social Capital formation, and therefore it is possible to evaluate their effectiveness qualitatively by measuring parental ties within the network against their levels of SC.

$\mathrm{SC}$ is a resource which like other forms of capital inequitable and reflects already existing inequalities (economic, social), and can enforce dominant ideology of certain groups. Those who get ahead through their social networks, often knowingly or unknowingly result in some being left behind. This is an important consideration for policy measures that set a goal for increased SC on micro or macro levels.

SC research is inconsistent particularly in the area of bonding and bridging SC. The findings show that bonding and bridging do not produce getting by and getting ahead benefits but contrariwise. 


\section{Implications}

\section{- Implications:}

1. Strong implications for the mediating role of a group facilitator to assist in Playgroup formation and as a continued support.

2. Policy implications for SC inequalities, when attempting to generate more SC across levels of organisations or communities.

3. Revision to the theoretical framework of bonding, bridging and linking SC is needed to account for empirical evidence of the 'real SC' as suggested by Hansell (1984) and Falk and Surata (2008) and supported by the findings in this study. 


\section{References}

Falk, I., \& Surata, K. (2007). Real' Social Capital in Bali: Is it different from 'The Literature'?. Rural Society 17(3) 308-323.

Hayden, J., De Gioia, K. \& Hadley, F. (2003). Enhancing supports and networks for families with children aged 0-5 years: The role of early childhood services. Paper presented at the Families First in Practice Conference, Sydney, October 9-10.

Leonard, R., \& Onyx, J. (2003). Networking through loose and strong ties: An Australian qualitative study. Voluntas: International Journal of Voluntary and Nonprofit Organizations 14(2) 189-203.

Stone, W. (2003). Towards building capacity and sustainable communities: Bonding, bridging and linking with social capital. Stronger Families Learning Exchange Bulletin. 4, 13-16.

Woolcock, M., \& Narayan, D. (2000). Social Capital: Implications for development theory, research, and policy. The World Bank Research Observer. 15(2) 225-249.

The author would like to thank all the parents who participated in this research, for sharing their valuable and insightful experiences so willingly and openly. 